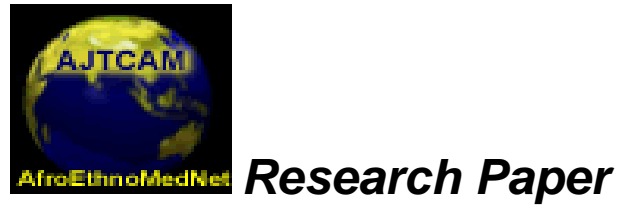

Afr. J. Traditional, Complementary and Alternative Medicines www.africanethnomedicines.net

ISSN 0189-6016@2009

\title{
COMPARING THE CYTOTOXIC POTENTIAL OF WITHANIA SOMNIFERA WATER AND METHANOL EXTRACTS
}

\author{
Etheresia Pretorius ${ }^{\star 1}$, Hester Magdalena Oberholzer ${ }^{1}$, Petrus Johannes Becker ${ }^{2}$ \\ ${ }^{1}$ Department of Anatomy, School of Health Sciences, Faculty of Health Sciences, University of \\ Pretoria, South Africa, ${ }^{2}$ Biostatistics Unit, Medical Research Council and Clinical Epidemiology, \\ University of Pretoria, South Africa \\ E-mail: * Etheresia Pretorius: resia.pretorius@up.ac.za,Hester Magdalena Oberholzer: \\ nanette.oberholzer@up.ac.za, Petrus Johannes Becker: pbecker@mrc.ac.za
}

\begin{abstract}
The plant Withania somnifera (Linn.) (Solanacea) is a well-known herbal medicine used in many parts of the world. It has anti-inflammatory, antioxidant, and antitumor as well as neural protective properties. It seems as if the two most active withanolide components, namely withaferin A and withanolide $\mathrm{D}$, found in methanol $(\mathrm{MeOH})$ extracts, are responsible for the anti-inflammatory and antioxidant properties of the plant. The current research evaluated and compared the cytotoxic potential of water and methanol extracts of $W$. somnifera using a combined crystal violet MTT and Neutral Red assay. MRC-5 cells, a human embryonic lung-derived diploid fibroblast cell line, were the cells of choice. We found that the three lowest concentrations $(0.007,0.042,0.250 \mu \mathrm{g} / \mathrm{ml})$ of the plant material extracted in double distilled $\mathrm{H}_{2} \mathrm{O}$ and $\mathrm{MeOH}$ do not differ significantly in any of the assays. We therefore suggest that low concentrations of $\mathrm{MeOH}$ extracts (up to $0.250 \mu \mathrm{g} / \mathrm{ml}$ plant material) do not cause cell damage to the MRC- 5 cells, however, higher levels should be avoided as cell viability and cell numbers are negatively influenced.
\end{abstract}

Key words: Withania somnifera, anti-inflammatory; water extract; methanol extract

\section{Introduction}

Withania somnifera (Linn.) is a member of the plant family Solanaceae and is also known as Ashwagandha, Indian Ginseng or Winter Cherry. It is an important component of the Ayurvedic pharmacopoeia of India, where it has been used for hundreds of years (Henderson and Anderson, 1966; Ahmad et al., 2005; Glaser, 1988). It has a wide distribution in Africa, Southern Europe and Asia, and is considered to be indigenous to South Africa (Henderson and Anderson, 1966). It also grows in the drier tropical regions and is also found from Liberia to Nigeria and the Southeast Islands (Iwu, 1993). 
The plant is chemically very complex and more than 80 compounds have been isolated (van Wyk et al., 2000). The withanolides (steroids with an ergostane skeleton), particularly Withaferin A, 3- $\beta$ hydroxy-2,3-dihydrowithanolide $F$ as well as Withanolide $D$ are of particular medicinal interest (Chu et al., 1988; van Wyk et al., 2000). Research has shown that $W$. somnifera has anti-inflammatory, antioxidant anti-tumour and immunomodulatory properties (Anbalagan and Sadique, 1981; Begum and Sadique, 1988; Somasundaram et al., 1983; Kulkarni et al., 1991; Al-Hindawi et al., 1992; Begum and Sadique, 1987; Bhattacharya et al., 1997; Parihar and Hemnani, 2003; Parihar et al., 2004).

Some of the important active compounds reported in the herb include the following: Withaferin $A$, sitoindosides VII-X, 5-dehydroxywithanolide-R, Withasomniferin-A, 1-oxo-5beta,6beta-epoxy-witha-2ene-27-ethoxy-olide,4-(1-hydroxy-2,2-methylcyclpropanone) $\quad$-2,3-dihydrowithaferin $\quad A, \quad 2,3-$ dihydrowithaferin A, 24,25-dihydro-27-desoxywithaferin A, physagulin D (1-6)-beta-D-glucopyranosyl-(14)-beta-D-glucopyranoside, 27-O-beta-D-glucopyranosylphysagulin D, physagulin D, Withanoside I-VII, 27-O-beta-D-glucopyranosylviscosalactone B, 4,16-dihydroxy-beta,6beta-epoxyphysagulin D, Viscosalactone B and Diacetylwithaferin A (Uma Devi, 1996; Ganzera et al., 2003; Jayaprakasam et al., 2003., Kaur et al., 2003; Matsuda et al., 2001).

The two most active Withanolide components, Withaferin $A$ and Withanolide $D$ are found in methanol extracts (Kuboyama et al., 2002; Ganzera et al., 2003; Choudhary et al., 2004). Also, the main antioxidant activity of $W$. somnifera was found in the methanol fraction (Parihar et al., 2004). Although water extracts are also known to have great medicinal potential, the methanol extracts seem to extract the active components the best. The question, however, arises whether the methanol extracts of the herb may be cytotoxic to cells in culture. Therefore, because of the potential use of the herb as an antiinflammatory product, the current research aimed to evaluate and compare the cytotoxic potential of water and methanol extracts of $W$. somnifera using a combined Crystal Violet assay, the MTT assay and the Neutral Red assay. The cells of choice were MRC-5 cells, which is a human embryonic lung-derived diploid fibroblast cell line. Statistical analyses were employed to determine whether there is a correlation between the two extract methods, as well as the concentrations used.

\section{Experimental Procedures Herb material}

Root material (WS1PRETORIA) was collected in the Pretoria area (South Africa) and identified by botanists from the Department of Botany, University of Pretoria, South Africa. A herbarium specimen was prepared and compared to an authentic specimen in the HGJW Sweikerdt herbarium at the University of Pretoria.

\section{Preparation of extracts}

Leaves, stems and roots were fragmented and dried at $45^{\circ} \mathrm{C}$ for $48 \mathrm{~h}$ and $\mathrm{MeOH}$ and water extracts were made. Plant material $\left(140 \mathrm{mg}\right.$ ) was added to $1,400 \mathrm{ml}$ double distilled (dd) $\mathrm{H}_{2} \mathrm{O}$ of water, yielding a final concentration of $100 \mathrm{mg}$ plant material per $\mathrm{ml} .2 .1039 \mathrm{~g}$ of $\mathrm{MeOH}$ extracted plant material was added to $4.2 \mathrm{ml} \mathrm{MeOH}$, yielding a final concentration of $0.5 \mathrm{~g}$ of plant material per $\mathrm{ml} \mathrm{MeOH}$. This was diluted 1:4 with dd $\mathrm{H}_{2} \mathrm{O}$, yielding a final concentration of $100 \mathrm{mg}$ plant material in $1 \mathrm{ml}$. Five concentrations of extracts of both $\mathrm{ddH}_{2} \mathrm{O}$ and $\mathrm{MeOH}$ were added to the cells in culture. The concentrations were: $0.007,0.042,0.250,1.151$, and $9.090 \mu \mathrm{g} / \mathrm{ml}$.

\section{MRC-5 Permanent cell line}

MRC-5 cells were obtained from Highveld Biological Company, Johannesburg, South Africa. The cells were plated at a cell concentration of $2 \times 10^{4}$ cells per $\mathrm{ml}$ in 24 flat well plates and were kept for $24 \mathrm{~h}$ at $37^{\circ} \mathrm{C}$ and $5 \% \mathrm{CO}_{2}$ before conducting the experiments. Solution of $100 \mathrm{mg} / \mathrm{ml}$ of each of the plant 
extracts was prepared either in dd $\mathrm{H}_{2} \mathrm{O}$ or $\mathrm{MeOH}$ and exposed to MRC-5 cells for $48 \mathrm{~h}$. The cytotoxicity of $\mathrm{MeOH}$ alone was also determined.

\section{Combined Crystal Violet, MTT and Neutral Red assay}

Cell number, cell viability and lysosomal membrane integrity, were determined using a combined Crystal Violet, MTT and Neutral Red (CV/MTT/NR) assay. To each well $100 \mu l 0.15 \%$ NR prepared in

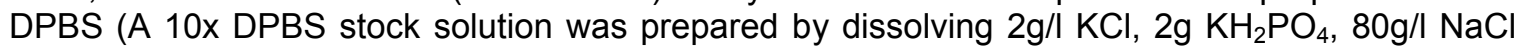
and $\mathrm{Na}_{2} \mathrm{HPO}_{4}$ in $\mathrm{ddH}_{2} \mathrm{O}$ that was diluted 1:9 with $\mathrm{ddH}_{2} \mathrm{O}$ prior to use) was added and then incubated for $90 \mathrm{~min}$ at $37^{\circ} \mathrm{C}$ in a $\mathrm{CO}_{2}$ incubator. A further $50 \mu \mathrm{l}$ volume of a $0.1 \mathrm{mg} / \mathrm{ml} 3-(4,5-$ Dimethylthiazol-2-yl)-2,5diphenyltetrazolium bromide (MTT) solution prepared in DPBS was added to each well and the cell culture plates were maintained for a further $60 \mathrm{~min}$ at $37^{\circ} \mathrm{C}$. The medium was then carefully removed and the plates were blotted dry. The cells were fixed for $10 \mathrm{~min}$ with $200 \mu \mathrm{l}$ of a $1 \%$ acetic acid and $1 \%$ formaldehyde solution in $\mathrm{ddH}_{2} \mathrm{O}$. The fixative was removed and the NR was solubilized with $200 \mu \mathrm{l}$ of a $1 \%$ acetic acid and $50 \%$ ethanol solution prepared in $\mathrm{ddH}_{2} \mathrm{O}$. The dissolved NR was transferred into a 96-flat well plate. The MTT formazan crystals were then dissolved with $200 \mu$ DMSO by shaking of the plates for 20 min before being transferred into a 96-flat well plate. Each well was washed once with DPBS and was dried in a microwave oven for a few mins at $60 \%$ power. The cells attached to the bottom of the plate were stained by adding a volume of $300 \mu \mathrm{l}$ of a $0.1 \%$ (weight/ volume $(\mathrm{w} / \mathrm{v}) \mathrm{CV}$ solution prepared in $200 \mathrm{mM}$ of formic acid pH 3.5, each well for $60 \mathrm{~min}$. After the microplate was washed with $\mathrm{ddH}_{2} \mathrm{O}$ and dried, the bound dye was dissolved in $10 \%$ acetic acid prepared in $\mathrm{dd}_{2} \mathrm{O}$. The solution was transferred to a 96-well and the absorbance of all bioassays was determined spectrophotometrically at $570 \mathrm{~nm}$ using the Microplate Reader (ELx800).

\section{Statistical analysis}

The experiment was conducted in a factorial design with main effects the extracts at two levels (plant material extracted in $\mathrm{ddH}_{2} \mathrm{O}$ and also in $\left.\mathrm{MeOH}\right)$ and concentration at five levels $(0.007,0.042$, $0.250,1.151$, and $9.090 \mu \mathrm{g} / \mathrm{ml}$ ). For each of the three assays the outcome variable was analysed in an appropriate analysis of variance (ANOVA) with two fixed effects, namely extract and concentration as well as the interaction. Pair-wise comparisons were done using the LSD method of Fisher. Testing was done at the 0.05 level of significance.

\section{Results and Discussion Combined Crystal Violet, MTT and Neutral Red assay}

The CV assay measures cell number in the presence of the 5 concentrations of the two extracts. All analyses were performed on the dataset and bar graphs of the results compiled (Figure $1-3$ ). From the ANOVA the two extracts differ significantly $(p=0.109)$ but not the concentrations $(p=0.5676)$. However, a significant interaction between extracts and concentrations exists $(p<0.0001)$. This interaction is displayed in Figure 1. Note that the first 3 concentrations of the two extracts react similarly but behave very differently over the last two concentrations, causing the significant difference between extracts $(p=0.0109)$ at these high concentrations, the $\mathrm{ddH}_{2} \mathrm{O}$ extract increased cell numbers, while the $\mathrm{MeOH}$ extract caused a decrease.

Figure 2 displays the results of the MTT assay, showing cell viability. ANOVA showed that the two extracts differ significantly $(p=0.0005)$ and that the concentrations also differ significantly $(p<$ 0.0001). In particular, following pair wise comparisons, the first three concentrations do not differ significantly but differ from the last two concentrations which also differ from each other. There is also a significant interaction between extract and concentration $(p=0.0110)$ which is clear from Figure 2 , where 
except for the fourth concentration the extracts behave similarly. However, what can be concluded from the graph is that cell viability decreases when using the two highest concentrations of the $\mathrm{MeOH}$ extract and the highest concentration of the $\mathrm{ddH}_{2} \mathrm{O}$ extract.

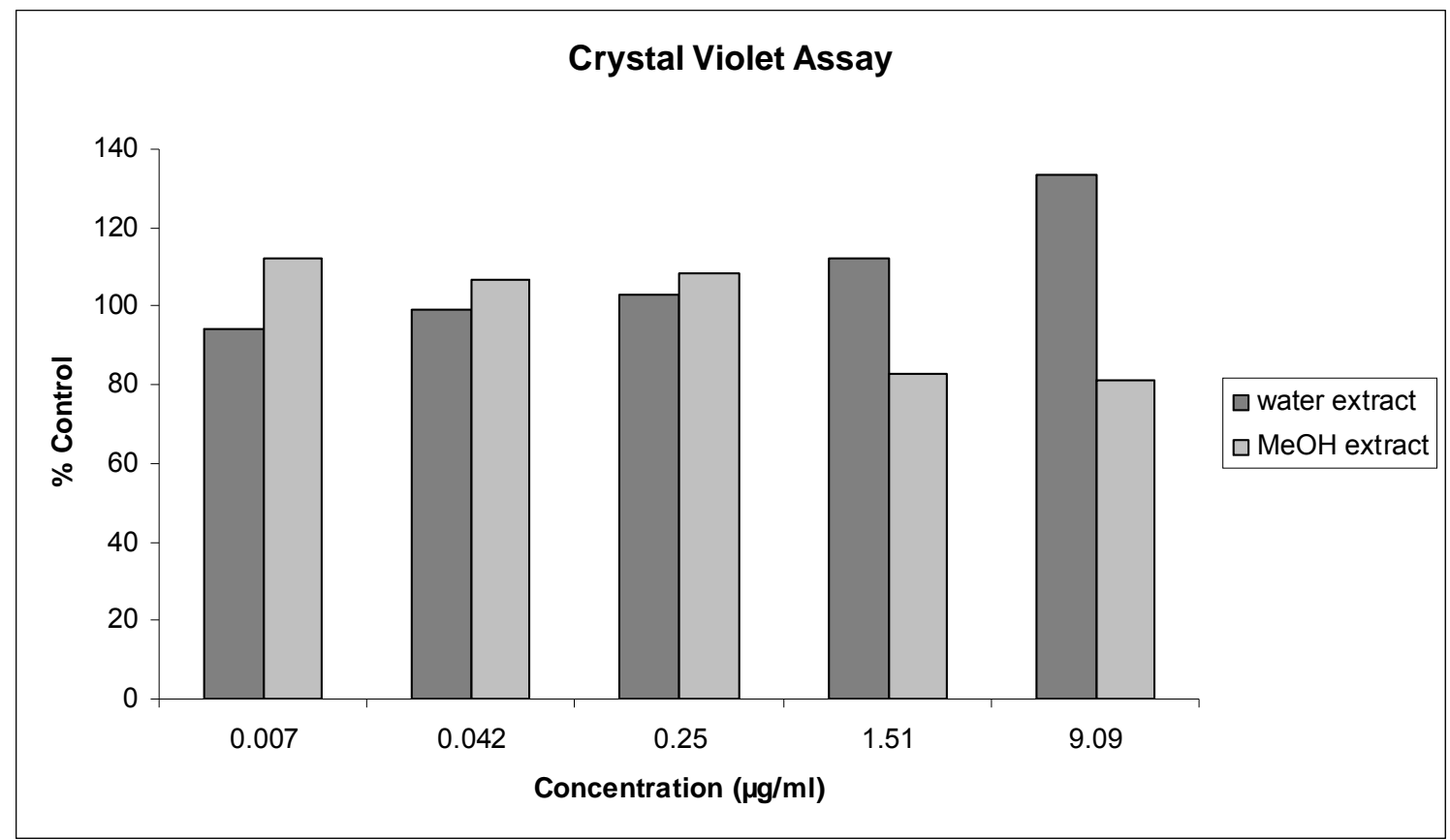

Figure 1: Effects of 5 concentrations of $W$. somnifera, extracted in $\mathrm{ddH}_{2} \mathrm{O}$ and $\mathrm{MeOH}$ and prepared in cell culture medium on MRC- 5 cell number after $48 \mathrm{~h}$ exposure: results from Crystal Violet Assay.

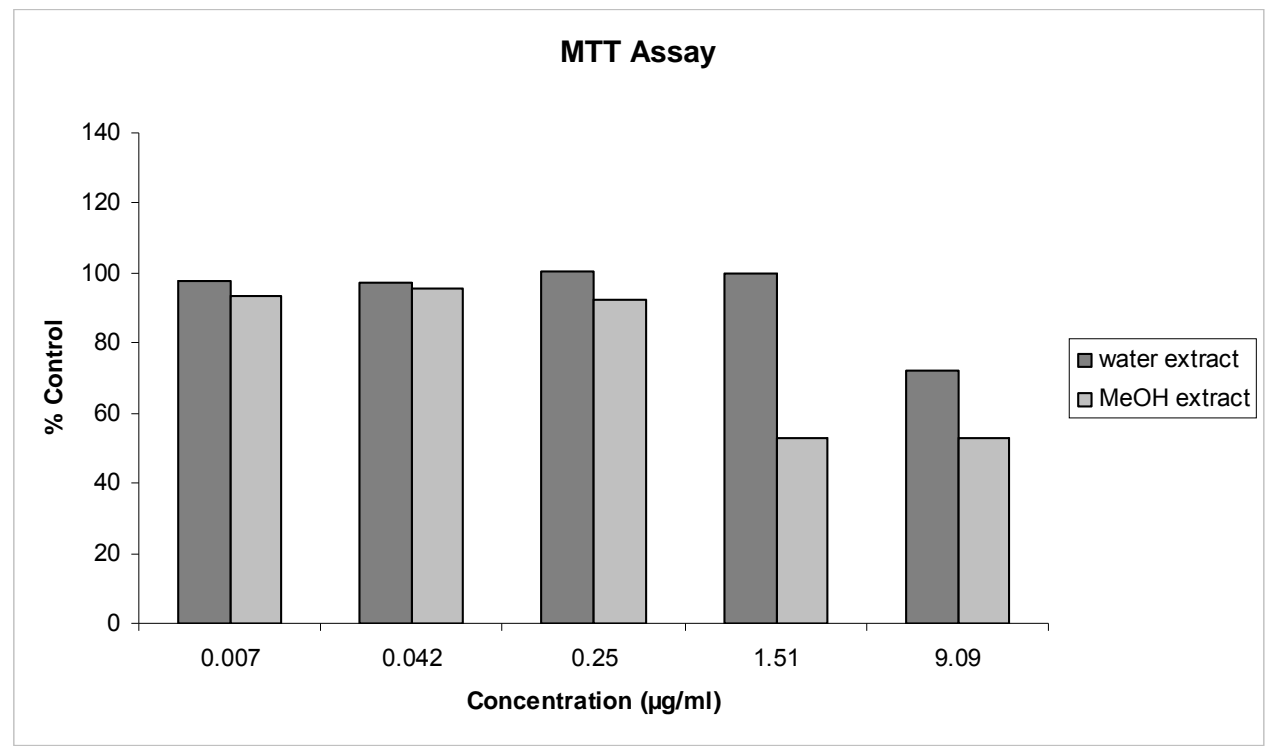

Figure 2: Effects of 5 concentrations of $W$. somnifera, extracted in $\mathrm{ddH}_{2} \mathrm{O}$ and $\mathrm{MeOH}$ and prepared in cell culture medium on MRC- 5 cell viability after $48 \mathrm{~h}$ exposure: results from MTT Assay. 


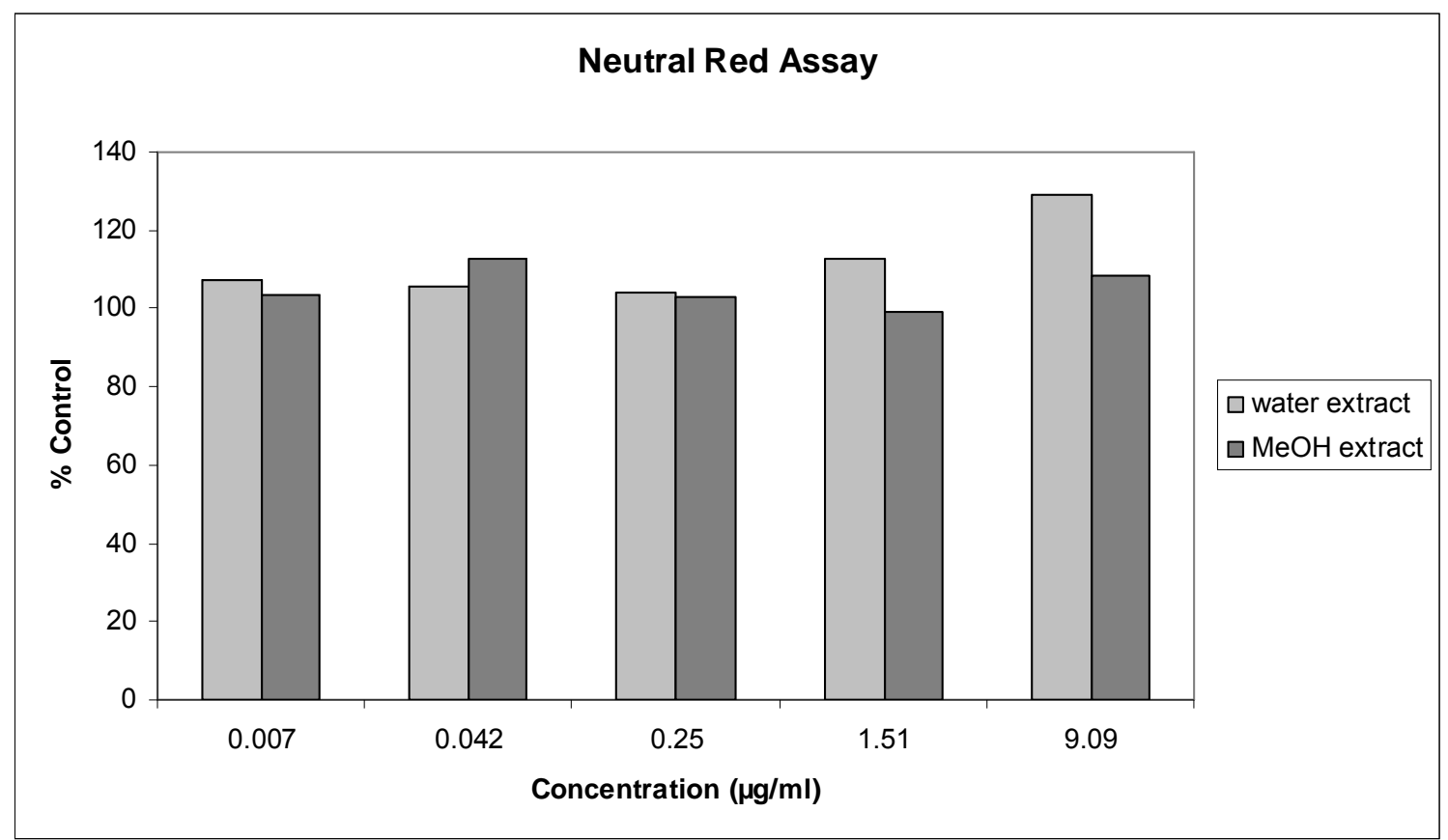

Figure 3: Effects of 5 concentrations of $W$. somnifera, extracted in $\mathrm{ddH}_{2} \mathrm{O}$ and $\mathrm{MeOH}$ and prepared in cell culture medium on MRC-5 lysosomal integrity after $48 \mathrm{~h}$ exposure: results from Neutral Red Assay.

The final assay, namely the NR assay, which determines lysosomal membrane integrity, is presented in Figure 3. ANOVA showed that respectively the extracts and the concentrations are significantly different $(p=0.0304$ and $p=0.0170)$. In particular, LSD pair-wise comparisons show that the first four concentrations do not differ significantly; however, these four concentrations differ from the highest concentration. The significant interaction between extract and concentration is also clear in Figure 3, where the two extracts behave similarly over the first three concentrations and quite differently over the last two concentrations.

We therefore conclude that the three lowest concentrations $(0.007,0.042$, and $0.250 \mu \mathrm{g} / \mathrm{ml})$ of the of the plant material extracted in $\mathrm{ddH}_{2} \mathrm{O}$ and $\mathrm{MeOH}$ seems not to be significantly different in any of the assays. At these three concentrations cell numbers, cell viability and lysosomal membrane activity were preserved.

Thus low concentrations of $\mathrm{MeOH}$ extracts (up to $0.250 \mu \mathrm{g} / \mathrm{ml}$ plant material) do not cause cell damage to the human embryonic lung-derived diploid fibroblast cell line, however, higher levels should be avoided as particularly cell viability and cell numbers are negatively influenced. The two active components Withaferin $A$ and Withanolide $D$ are most successfully extracted using $\mathrm{MeOH}$ (Kuboyama et al., 2002; Ganzera et al., 2003; Choudhary et al., 2004). Research therefore investigating the antiinflammatory or antioxidant activity of $W$. somnifera can use $\mathrm{MeOH}$ extracts, but care should be taken not to use concentrations that are too high.

\section{Acknowledgements}

We thank the National Research Foundation for funding both E. Pretorius (Indigenous Knowledge Systems: FA2004033100004 


\section{References}

1. Ahmad M., Saleem S., Ahmad A.S., Ansari M. A., Yousuf S and Hoda N (2005). Neuroprotective effects of Withania somnifera on 6-hydroxydopamine induced Parkinsonism in rats. Hum Exp Toxicol, 24(3): 137-147.

2. Al-Hindawi, M.K., al-Khafaji, S.H. and Abdul-Nabi, M.H., (1992). Anti-granuloma activity of Iraqi Withania somnifera. J Ethnopharmacol, 37:113-116.

3. Anbalagan, K. and Sadique, J., (1981). Influence of an Indian medicine (Ashwagandha) on acute-phase reactants in inflammation. Indian J Exp Biol, 19: 245-9.

4. Begum, V.H. and Sadique, J., (1987). Effect of Withania somnifera on glycosaminoglycan synthesis in carrageenin-induced air pouch granuloma. Biochem Med Metab Biol, 38: 272-7.

5. Begum V.H. and Sadique J., (1988). Long term effect of herbal drug Withania somnifera on adjuvant induced arthritis in rats. Indian J Exp Biol, 26: 877-882

6. Bhattacharya, S.K., Satyan, K.S. and Ghosal, S., (1997). Antioxidant activity of glycowithanolides from Withania somnifera. Indian J Exp Biol, 35: 236-9.

7. Choudhary, M.I., Yousuf, S., Nawaz, S.A., Ahmed, S. and Atta-ur-Rahman, A., (2004). Cholinesterase inhibiting withanolides from Withania somnifera. Chem Pharm Bull, 52:1358-61.

8. Chu, D.T., Wong, W. and Mavligit, G.M., (1988), Immunotherapy with Chinese medicinal herbs. I. Immune restoration of local xenogeneic graft-versus-host reaction in cancer patients by fractionated Astragalus membranaceus in vitro. J Clin Lab Immunol, 25:119-129.

9. Ganzera, M., Choudhary, M.I. and Khan, I.A., (2003). Quantitative HPLC analysis of withanolides in Withania somnifera. Fitoterapia, 74:68-76.

10. Glaser J.L., (1988). Maharishi Ayurveda: an introduction to recent research. Modern Science and Vedic Science, 2 (1): 89-108

11. Henderson, M. and Anderson, J.G., (1966). Common weeds in South Africa. Memoirs of the Botanical Survey of South Africa, 37: 286

12. Iwu M.M., (1993). Handbook of African Medicinal Plants. Florida, USA: CRC Press

13. Jayaprakasam B., Zhang Y., Seeram N.P. and Nair M.G., (2003). Growth inhibition of human tumor cell lines by withanolides from Withania somnifera leaves. Life Sci, 74: 125-32

14. Kaur P., Sharma M., Mathur S., Tiwari M., Divekar H. M., Kumar R., Srivastava K. K. and Chandra R (2003). Effect of 1-oxo-5beta, 6beta-epoxy-with a-2-ene 27-ethoxy-olide isolated from the roots of Withania somnifera on stress indices in Wistar rats. J Altern Complement Med, 9: 897-907

15. Kuboyama, T., Tohda, C., Zhao, J., Nakamura, N., Hattori, M. and Komatsu, K., (2002). Axon- or dendritepredominant outgrowth induced by constituents from Ashwagandha. Neuroreport, 13:1715-20.

16. Kulkarni, R.R., Patki, P.S., Jog, V.P., Gandage, S.G. and Patwardhan, B., (1991). Treatment of osteoarthritis with a herbomineral formulation: a double-blind, placebo-controlled, cross-over study. J Ethnopharmacol, 33: 91-5.

17. Matsuda H., Murakami T., Kishi A. and Yoshikawa M., (2001). Structures of Withanolides I, II, III, IV, V, VI and VII, new withanolide glycosides, from roots of Indian Withania somnifera DUNAL and inhibitory activity for tachyphylaxis to clonidine in isolated guinea-pig ileum. Bioorg Med Chem, 9: 1499-507

18. Parihar, M.S., Chaudhary, M., Shetty, R. and Hemnani, T., (2004). Susceptibility of hippocampus and cerebral cortex to oxidative damage in streptozotocin treated mice: prevention by extracts of Withania somnifera and Aloe vera. J Clin Neurosci, 11: 397-402.

19. Parihar, M.S. and Hemnani, T., (2003). Phenolic antioxidants attenuate hippocampal neuronal cell damage against kainic acid induced excitotoxicity. J Biosci, 28:121-8.

20. Schroter, H.B., Neumann, D., Katritzky, A.R. and Swinborne, F., (1966). Withasomnine, a pyrazole alkaloid from Withania somnifera. Tetrahedron Lett (London), 22: 2895 -2897.

21. Somasundaram, S., Sadique, J. and Subramoniam, A., (1983). In vitro absorption of [14C]leucine during inflammation and the effect of antiinflammatory drugs in the jejunum of rats. Biochem Med, 29: 259-64.

22. Uma Devi P. (1996). Withania somnifera dunal (Ashwagandha): potential plant source of promising drug for cancer chemotherapy and radiosensitization. Indian J Exp Biol, 34: 927-32

23. Van Wyk, B.E., Van Oudtshoorn, B. and Gericke, N., (2000). Medicinal plants of South Africa. Briza publications, pp. 38-39. 